Arq. Bras. Med. Vet. Zootec., v.56, n.2, p.150-156, 2004

\title{
Criptorquismo em eqüinos: aspectos clínico-cirúrgicos e determinação da testosterona sérica
}

[Cryptorchism in horses: clinical and surgical aspects and serum testosterone determination]

\author{
J.W. Cattelan ${ }^{1}$, D.G. Macoris ${ }^{1}$, P.A. Barnabé ${ }^{2}$, E.C. Urbinati ${ }^{1}$, E.B. Malheiros ${ }^{1}$ \\ ${ }^{1}$ Faculdade de Ciências Agrárias e Veterinárias - UNESP - Campus de Jaboticabal \\ Via de Acesso Prof. Paulo Donato Castellane, s/n. \\ 14884-900 - Jaboticabal, SP \\ ${ }^{2}$ Doutoranda em Cirurgia Veterinária - UNESP-Jaboticabal
}

\begin{abstract}
RESUMO
Alguns aspectos clínico-cirúrgicos do criptorquismo foram investigados em 42 eqüinos. A freqüência da afecção foi elevada em cavalos Mangalarga, Quarto de Milha e sem raça definida que, em conjunto, totalizaram $73,8 \%$ dos casos. O criptorquismo abdominal $(64,3 \%)$ predominou sobre o inguinal $(35,7 \%)$. A retenção unilateral ocorreu na maioria dos casos $(95,2 \%)$, com prevalência do criptorquismo abdominal unilateral esquerdo $(45,2 \%)$. Também foi determinada a concentração da testosterona sérica em seis garanhões normais (grupo I) em plena atividade sexual (grupo-controle) e em 10 criptórquios (grupos II e III, respectivamente, cinco abdominais e cinco inguinais). A dosagem da testosterona sérica não revelou diferença $(\mathrm{P}>0,05)$ entre os três grupos. Os achados indicam que a produção desse hormônio permanece inalterada no criptórquio, justificando seu comportamento sexual, semelhante ao do garanhão normal.
\end{abstract}

Palavras-chave: criptorquismo, testosterona, eqüino

\begin{abstract}
Some clinical and surgical aspects of the cryptorchism were investigated in 42 horses. Cryptorchism had a high frequency in Mangalarga, Quarter Horse, and mixed breed, 73.8\% of the cases. Abdominal cryptorchism was more prevalent than the inguinal, $64.3 \%$ and $35.7 \%$, respectively. The unilateral retention occurred in most cases (95.2\%), with a high frequency of left abdominal cryptorchism (45.2\%). The serum testosterone levels were also determined in six normal stallions (control group) and 10 cryptorchid horses (five abdominals and five inguinals). Serum testosterone concentration showed no difference $(P>0.05)$ among groups. The production of this hormone did not change in the cryptorchism, therefore, justifying the similar sexual behavior of the cryptorchid horse and normal stallions.
\end{abstract}

Keywords: cryptorchism, testosterone, horse

\section{INTRODUÇÃO}

O criptorquismo em eqüinos é uma condição relativamente comum e tem particular importância, uma vez que o animal afetado apresenta todas as características de comportamento do garanhão normal (Smith, 1975). A afecção ocorre em várias raças (Hayes, 1986), sendo citada elevada freqüência na Quarto de Milha (Stickle, Fessler, 1978; Hayes, 1986), “American Saddlebred", Percheron, em animais mestiços ou sem raça definida (Hayes, 1986) e pôneis (Wright, 1960, 1963; Cox et al., 1979; Hayes, 1986).

A criptorquia unilateral é mais comum que a bilateral (Arighi et al., 1988; Ladds, 1993; Ackland, 2001; Nascimento, Santos, 2003) e a

Recebido para publicação em 24 de abril de 2003

Recebido para publicação, após modificações, em 13 de outubro de 2003

E-mail: cattelan@fcav.unesp.br 
prevalência de retenção dos testículos à esquerda ou à direita é quase igual (Stickle, Fessler, 1978; Cox et al., 1979). Entretanto, gônadas retidas do lado esquerdo geralmente são abdominais, enquanto as do antímero direito parecem distribuir-se igualmente entre inguinais e abdominais (Stanic, 1960; Stickle, Fessler, 1978; Cox et al., 1979).

O diagnóstico do criptorquismo envolve conhecimento do histórico completo, onde o comportamento de garanhão é evidenciado e associado ao exame de palpação externa (Bergin et al., 1970; Trotter, Aaanes, 1981), no qual as áreas escrotal e inguinal são cuidadosamente exploradas, visando a percepção do testículo ou de cicatriz de intervenção cirúrgica anterior (Trotter, Aanes, 1981). O exame interno por palpação retal, objetivando a identificação da gônada e dos anéis vaginais e/ou inguinais internos (Bergin et al., 1970), fornece resultados contraditórios devido à mobilidade e consistência flácida do testículo retido (Stickle, Fessler, 1978; Leipold et al., 1986).

Em cavalos com histórico desconhecido e sem testículos palpáveis no escroto, o método diagnóstico mais confiável é a dosagem hormonal de androgênios ou estrogênios, pois garanhões e criptórquios têm concentrações séricas dessas substâncias mais elevadas do que os castrados (Cox et al., 1973, 1986; Cox, 1982, 1989; Arighi, Bosu, 1989). Alguns ensaios envolvendo determinação da testosterona sérica mostraram valores médios semelhantes entre garanhões e criptórquios (Coryn et al., 1981; Arighi et al., 1986).

O tratamento cirúrgico do criptorquidismo envolve diferentes procedimentos operatórios conforme a localização da gônada retida. No criptorquismo inguinal, indica-se a criptorquidectomia inguinal (Stanic, 1960; Stickle, Fessler, 1978; Valdez et al., 1979). Na retenção abdominal também há possibilidade de orquiectomia por via inguinal, bem como pela laparo-criptorquidectomia por incisão paramediana paraprepucial ou suprapúbica (Wright, 1960, 1963; Lowe, Higginbotham, 1969; Cox et al., 1975; Silva et al., 2002), pela laparotomia parainguinal (Wilson, Reinertson, 1987) ou pela de flanco (Marques, Ferreira, 1987).
Os objetivos desta pesquisa incluem a obtenção de dados clínico-cirúrgicos do criptorquismo em cavalos, determinando-se a freqüência e distribuição da afecção, com interesse na raça, idade, classificação da retenção e procedimento cirúrgico usado no tratamento, além da mensuração da testosterona sérica em três grupos de eqüinos.

\section{MATERIAL E MÉTODOS}

Foram utilizados 42 cavalos criptórquios de raças e idades diversas.

Para dosagem da testosterona sérica foram formados três grupos de animais, sendo um de cavalos criptórquios abdominais $(n=5)$, outro de criptórquios inguinais $(n=5)$ e o terceiro por garanhões sadios em atividade sexual (grupocontrole, $n=6$ ).

Amostras sangüíneas foram colhidas pela manhã, por punção na jugular, obtendo-se $20 \mathrm{ml}$ de sangue acondicionados em frasco estéril sem anticoagulante. $O$ sangue foi centrifugado a $1500 \mathrm{G}$ durante 10 minutos para obtenção de soro, que foi dividido em alíquotas de $3,0 \mathrm{ml}$ e mantido sob congelamento $\left(-20^{\circ} \mathrm{C}\right)$ para posterior dosagem hormonal.

As dosagens de testosterona foram realizadas pelo método de radioimunoensaio (RIE), utilizando-se reagente comercial $^{1}$, com o hormônio sendo marcado com $\mathrm{I}^{125}$ (traçador radioativo). A radioatividade foi medida por contador automático ${ }^{2}$ para determinação da curva padrão e da concentração das amostras.

Os valores obtidos foram submetidos à análise de variância (teste $\mathrm{F}$ ), considerando-se delineamento inteiramente ao acaso, com três tratamentos: controle (seis repetições), criptórquio abdominal (cinco repetições) e criptórquio inguinal (cinco repetições).

\section{RESULTADOS}

A distribuição dos achados nos eqüinos criptórquios encontra-se na Tab. 1 .

\footnotetext{
${ }^{1}$ Total Testosterone - Coat-A-Count ${ }^{\circledR}$ - DPC - Los Angeles - CA - USA

${ }^{2}$ Gamma Counter - DPC - Los Angeles - CA - USA
} 
Tabela 1. Distribuição do criptorquismo em cavalos segundo raça, idade, classificação da afecção e verificação de hemi-castração pela identificação de testículo escrotal

\begin{tabular}{|c|c|c|c|c|}
\hline Raça & Idade & Tipo de criptorquismo & Hemi-castração & Gônada escrotal \\
\hline Mangalarga & $2 \mathrm{a}$ e $6 \mathrm{~m}$ & Abdominal esquerdo & Não & Presente $=\mathrm{D}$ \\
\hline Mangalarga & $5 a$ & Abdominal esquerdo & Não & Presente $=\mathrm{D}$ \\
\hline Mangalarga & $3 a$ & Abdominal esquerdo & Não & Presente $=\mathrm{D}$ \\
\hline Mangalarga & $4 a$ & Abdominal direito & Não & Presente $=\mathrm{E}$ \\
\hline Mangalarga & $4 \mathrm{a}$ & Abdominal direito & Sim & Ausente $=\mathrm{E}$ \\
\hline Mangalarga & $3 a$ & Abdominal bilateral & Não & Ausentes \\
\hline Mangalarga & $4 \mathrm{a}$ e $1 \mathrm{~m}$ & Inguinal direito & Não & Presente $=\mathrm{E}$ \\
\hline Mangalarga & $5 a$ & Inguinal direito & Não & Presente $=\mathrm{E}$ \\
\hline Mangalarga & $4 \mathrm{a}$ e $6 \mathrm{~m}$ & Inguinal direito & Sim & Ausente $=\mathrm{E}$ \\
\hline Mangalarga & $2 \mathrm{a}$ e $6 \mathrm{~m}$ & Inguinal direito & Sim & Ausente $=\mathrm{E}$ \\
\hline Mangalarga & $3 a$ & Inguinal direito & Sim & Ausente $=\mathrm{E}$ \\
\hline Mangalarga & $4 \mathrm{a}$ & Inguinal esquerdo & Sim & Ausente $=\mathrm{D}$ \\
\hline Quarto de Milha & $8 \mathrm{a}$ & Abdominal esquerdo & Sim & Ausente $=\mathrm{D}$ \\
\hline Quarto de Milha & $2 \mathrm{a}$ e $6 \mathrm{~m}$ & Abdominal esquerdo & Sim & Ausente $=\mathrm{D}$ \\
\hline Quarto de Milha & $4 a$ e $6 m$ & Abdominal esquerdo & Sim & Ausente $=\mathrm{D}$ \\
\hline Quarto de Milha & $4 a$ & Abdominal esquerdo & Não & Presente $=\mathrm{D}$ \\
\hline Quarto de Milha & $4 \mathrm{a}$ e $2 \mathrm{~m}$ & Abdominal esquerdo & Não & Presente $=\mathrm{D}$ \\
\hline Quarto de Milha & $2 \mathrm{a}$ e $6 \mathrm{~m}$ & Abdominal esquerdo & Não & Presente $=\mathrm{D}$ \\
\hline Quarto de Milha & $3 a$ & Abdominal direito & Sim & Ausente $=\mathrm{E}$ \\
\hline Quarto de Milha & $5 \mathrm{a}$ e $7 \mathrm{~m}$ & Abdominal direito & Não & Presente $=\mathrm{E}$ \\
\hline Quarto de Milha & $4 a$ & Abdominal bilateral & Não & Ausentes \\
\hline Quarto de Milha & $3 a$ & Inguinal direito & Sim & Ausente $=\mathrm{E}$ \\
\hline Quarto de Milha & $5 \mathrm{a}$ & Inguinal direito & Não & Presente $=\mathrm{E}$ \\
\hline Sem Raça Definida & $3 a$ & Abdominal esquerdo & Não & Presente $=$ D \\
\hline Sem Raça Definida & $5 \mathrm{a}$ & Abdominal esquerdo & Não & Presente $=D^{*}$ \\
\hline Sem Raça Definida & $10 \mathrm{a}$ & Abdominal esquerdo & Sim & Ausente $=\mathrm{D}$ \\
\hline Sem Raça Definida & $4 a$ & Abdominal esquerdo & Sim & Ausente $=\mathrm{D}$ \\
\hline Sem Raça Definida & $5 \mathrm{a}$ & Abdominal direito & Sim & Ausente $=\mathrm{E}$ \\
\hline Sem Raça Definida & $5 a$ & Inguinal direito & Não & Presente $=\mathrm{E}$ \\
\hline Sem Raça Definida & $5 \mathrm{a}$ & Inguinal direito & Não & Presente $=\mathrm{E}$ \\
\hline Sem Raça Definida & $5 a$ & Inguinal esquerdo & Não & Presente $=\mathrm{D}$ \\
\hline Brasileiro de Hipismo & $2 \mathrm{a}$ e $6 \mathrm{~m}$ & Abdominal esquerdo & Sim & Ausente $=\mathrm{D}$ \\
\hline Brasileiro de Hipismo & $3 a$ e $6 m$ & Abdominal esquerdo & Sim & Ausente $=\mathrm{D}$ \\
\hline Brasileiro de Hipismo & $4 a$ & Abdominal esquerdo & Não & Presente $=\mathrm{D}$ \\
\hline Brasileiro de Hipismo & $2 \mathrm{a} \mathrm{e} 11 \mathrm{~m}$ & Inguinal direito & Não & Presente $=\mathrm{E}$ \\
\hline Brasileiro de Hipismo & $5 \mathrm{a}$ e $2 \mathrm{~m}$ & Inguinal direito & Não & Presente $=\mathrm{E}$ \\
\hline Brasileiro de Hipismo & $2 \mathrm{a}$ e $6 \mathrm{~m}$ & Inguinal direito & Não & Presente $=\mathrm{E}$ \\
\hline Piquira & $5 a$ & Abdominal esquerdo & Sim & Ausente $=\mathrm{D}$ \\
\hline Piquira & $6 a$ & Abdominal esquerdo & Sim & Ausente $=\mathrm{D}$ \\
\hline Puro Sangue Andaluz & $7 a$ & Abdominal esquerdo & Sim & Ausente $=\mathrm{D}$ \\
\hline Puro Sangue Andaluz & $4 \mathrm{a}$ & Inguinal direito & Não & Presente $=\mathrm{E}$ \\
\hline Puro Sangue Inglês & $5 \mathrm{a}$ & Abdominal direito & Não & Presente $=\mathrm{E}$ \\
\hline
\end{tabular}

$\mathrm{a}=$ anos; $\mathrm{m}=$ meses; $\mathrm{D}=$ direito; $\mathrm{E}=$ esquerdo

*= Testículo escrotal não removido por decisão do proprietário.

Foram registrados 42 casos de criptorquismo em cavalos, $12(28,6 \%)$ da raça Mangalarga, 11 $(26,2 \%)$ na Quarto de Milha, oito $(19,1 \%)$ em animais sem raça definida, seis $(14,3 \%)$ na Brasileiro de Hipismo, dois (4,8\%) na Piquira, dois $(4,8 \%)$ na Puro Sangue Andaluz e um $(2,4 \%)$ na Puro Sangue Inglês.

Dentre os animais acometidos, $14 \quad(33,3 \%)$ tinham entre dois e meio e três e meio anos de idade, $25(59,5 \%)$ entre quatro e seis anos, um $(2,4 \%)$ com sete anos, um $(2,4 \%)$ com oito e outro $(2,4 \%)$ com 10 anos.

A forma mais freqüente de criptorquismo foi a abdominal unilateral esquerda com 19 casos $(45,2 \%)$, seguida pela inguinal unilateral direita, 13 registros $(31,0 \%)$ e abdominal unilateral direita, seis observações (14,3\%). Foram registrados dois casos $(4,8 \%)$ de criptorquia 


\section{Criptorquismo em eqüinos...}

abdominal bilateral e dois $(4,8 \%)$ de criptorquidia inguinal unilateral esquerda.

Dos 42 cavalos criptórquios, $22(52,4 \%)$ ainda tinham a gônada escrotal e em 18 (42,9\%) ela já havia sido extirpada antes.

Nos 27 casos de criptorquismo abdominal, o acesso cirúrgico mais utilizado para remoção da gônada retida foi a laparotomia paramediana paraprepucial, 25 pacientes $(92,6 \%)$, inclusive nos portadores da retenção abdominal bilateral, nos quais foram feitas duas incisões, uma em cada antímero. Entretanto, em um animal (3,7\%) a gônada abdominal foi removida por criptorquidectomia inguinal e em outro $(3,7 \%)$, por laparotomia parainguinal.

Nos 15 criptórquios inguinais, a gônada afetada foi removida por criptorquidectomia inguinal.

Dos 22 cavalos que ainda tinham o testículo escrotal, em 21 ele foi extirpado por orquiectomia convencional, e em um a gônada não foi removida por decisão do proprietário.

Os valores da dosagem da testosterona sérica ( $\mathrm{ng} / \mathrm{ml})$ encontram-se na Tab. 2 e os resultados da análise estatística estão sumariados na Tab. 3.

Tabela 2. Concentrações da testosterona sérica $(\mathrm{ng} / \mathrm{ml})$ em cavalos dos grupos controle e criptórquios abdominal e inguinal

\begin{tabular}{lccc}
\hline Raça & Idade & Grupo & Testosterona (ng/ml) \\
\hline Mangalarga & $4 \mathrm{a}$ & Controle & 0,7400 \\
Mangalarga & $4 \mathrm{a}$ & Controle & 0,9536 \\
Mangalarga & $4 \mathrm{a}$ & Controle & 0,7105 \\
Mangalarga & $6 \mathrm{a}$ & Controle & 0,2132 \\
Sem Raça Definida & $7 \mathrm{a}$ & Controle & 0,5291 \\
Quarto de Milha & $5 \mathrm{a}$ & Controle & 0,4423 \\
Quarto de Milha & $4 \mathrm{a}$ & Criptórquio abdominal & 0,7617 \\
Quarto de Milha & $4 \mathrm{a}$ e $2 \mathrm{~m}$ & Criptórquio abdominal & 0,4791 \\
Brasileiro de Hipismo & $2 \mathrm{a} \mathrm{e} \mathrm{6m}$ & Criptórquio abdominal & 0,2189 \\
Brasileiro de Hipismo & $3 \mathrm{a}$ e 6m & Criptórquio abdominal & 0,6444 \\
Sem Raça Definida & $4 \mathrm{a}$ & Criptórquio abdominal & 0,8555 \\
Quarto de Milha & $3 \mathrm{a}$ & Criptórquio inguinal & 0,1736 \\
Quarto de Milha & $5 \mathrm{a}$ & Criptórquio inguinal & 0,6411 \\
Mangalarga & $4 \mathrm{a} \mathrm{e} \mathrm{6m}$ & Criptórquio inguinal & 0,3246 \\
Mangalarga & $2 \mathrm{a}$ e $6 \mathrm{~m}$ & Criptórquio inguinal & 0,7013 \\
Brasileiro de Hipismo & $2 \mathrm{a} \mathrm{e} 6 \mathrm{~m}$ & Criptórquio inguinal & 0,5514 \\
\hline
\end{tabular}

$\mathrm{a}=$ anos; $\mathrm{m}=$ meses.

Tabela 3. Valores de F, coeficiente de variação (CV) e médias obtidas na análise de variância para testosterona sérica

\begin{tabular}{lc}
\hline F para grupos & $0,39 \mathrm{NS}$ \\
$\mathrm{CV}$ & $44,04 \%$ \\
Média do grupo-controle $(\mathrm{n}=6)$ & $0,5981 \mathrm{ng} / \mathrm{ml}$ \\
Média do grupo criptórquio abdominal $(\mathrm{n}=5)$ & $0,5919 \mathrm{ng} / \mathrm{ml}$ \\
Média do grupo criptórquio inguinal $(\mathrm{n}=5)$ & $0,4784 \mathrm{ng} / \mathrm{ml}$ \\
\hline
\end{tabular}

$\mathrm{NS}=$ não significativo.

$\mathrm{Na}$ comparação entre os grupos controle e criptórquios abdominal e inguinal não foram observadas diferenças significativas $(\mathrm{P}>0,05)$ quanto à concentração sérica de testosterona (Tab. 3).

\section{DISCUSSÃO}

Neste estudo, a maior freqüência de criptorquismo foi verificada nos eqüinos Mangalarga, Quarto de Milha e sem raça definida que, em conjunto, totalizaram 31 casos $(73,8 \%)$. Entretanto, outro estudo nacional 
apontou maior incidência em cavalos sem raça definida, seguida pela Mangalarga e Campolina (Marques, Ferreira, 1987), enquanto pesquisas internacionais citaram a Quarto de Milha (Stickle, Fessler, 1978; Hayes, 1986), animais sem raça definida (Hayes, 1986) e pôneis (Wright, 1960, 1963; Cox et al., 1979; Hayes, 1986), indicando grande variação entre as raças mais acometidas. É provável que tal distribuição racial nas casuísticas citadas possa ser influenciada pelas raças predominantes nos criatórios, sociedades hípicas e esportivas existentes próximas aos centros de referência onde os animais são atendidos, não significando que seja, necessariamente, mais freqüente nelas.

O criptorquismo unilateral foi constatado em 40 cavalos $(95,2 \%)$, sendo 21 casos $(52,5 \%)$ na gônada esquerda e $19(47,5 \%)$ na direita, confirmando os estudos de Stickle e Fessler (1978) e Cox et al. (1979), que relataram freqüência praticamente igual de retenção nos testículos esquerdo e direito. A afecção foi abdominal bilateral em $4,8 \%$ dos casos, próxima aos 3,8\% obtidos por Lowe e Higginbotham (1969).

A forma mais freqüente de criptorquismo neste estudo foi a abdominal, 27 registros $(64,3 \%)$, dos quais $19(45,2 \%)$ envolviam o testículo esquerdo, seis $(14,3 \%)$ o direito, e dois $(4,8 \%)$ ambos. Estes achados assemelham-se aos de Stanic (1960) e Stickle e Fessler (1978), que observaram elevada percentagem de retenção da gônada esquerda na cavidade abdominal. Bergin et al. (1970) e Ackland (2001) afirmaram que, no cavalo, o criptorquismo unilateral esquerdo predomina sobre o direito, podendo ser explicado pela descida relativamente mais lenta do epidídimo e testículo esquerdos. Segundo Smith (1975), durante o estágio de regressão testicular, a gônada direita do feto tende a ficar menor que a esquerda, o que pode justificar a maior freqüência de criptorquismo abdominal unilateral esquerdo.

Provavelmente a maior ocorrência de criptorquismo abdominal relaciona-se à idade dos animais operados, pois neste estudo foram considerados criptórquios somente cavalos com idade igual ou superior a 30 meses. Isso também foi verificado por Marques e Ferreira (1987), em animais entre 36 e 48 meses de idade. No estudo de Silva et al. (2002), com eqüinos de três a 10 anos de idade, o criptorquismo inguinal ocorreu em $70,4 \%$ dos casos, o que representa o dobro do valor encontrado nesta pesquisa $(35,7 \%)$. Na literatura internacional há relatos de maior freqüência do criptorquismo inguinal (Cox et al., 1979; Coryn et al., 1981), incluindo animais com menor idade, a partir de um ano. Cox et al. (1979) e Coryn et al. (1981) também observaram que a proporção entre retenção inguinal e abdominal decresce com o avançar da idade.

O acesso cirúrgico mais usado para remoção das gônadas criptórquias abdominais foi a laparotomia paramediana paraprepucial, tida como via de acesso segura, eficaz e com poucas complicações pós-operatórias (Wright, 1960, 1963; Lowe, Higginbotham, 1969; Cox et al., 1975). Todavia, outras abordagens são factíveis e, conforme praticado nesta pesquisa, pode-se remover o testículo abdominal por laparotomia parainguinal (Wilson, Reinertson, 1987) ou por via inguinal (Stanic, 1960; Stickle, Fessler, 1978; Valdez et al., 1979). Em todos os casos de criptorquismo inguinal, os testículos afetados foram extirpados por criptorquidectomia inguinal, o que também foi recomendado por Stanic (1960), Stickle e Fessler (1978) e Valdez et al. (1979).

Neste estudo, as gônadas escrotais também foram extirpadas (exceto em um animal) pelo fato de haver elevado risco de desenvolvimento de neoplasias (Ackland, 2001). Além disso, as gônadas escrotais de criptórquios unilaterais são funcionais, assim esses animais devem ser castrados, devido à natureza hereditária da afecção (Leipold et al., 1986; Nascimento, Santos, 2003).

A concentração sérica de testosterona em garanhões e cavalos criptórquios foi semelhante, aspecto já verificado por Coryn et al. (1981) e Arighi et al. (1986). Isto mostra que sua produção permaneceu inalterada no criptórquio, justificando seu comportamento sexual.

Com freqüência eqüinos criptórquios são encaminhados a hospitais veterinários após terem sido castrados no campo, com extirpação exclusiva da gônada localizada no escroto, originando o "hemi-castrado" (Arighi et al., 1988). A detecção desses casos pode ser obtida pela dosagem da testosterona sérica (Cox et al., 1973, 1986; Coryn et al., 1981; Cox, 1982, 1989; 
Arighi et al., 1986; Arighi, Bosu, 1989), procedimento confiável e com pequena margem de erro (Arighi, Bosu, 1989). A dosagem do hormônio auxilia o reconhecimento do animal que apresenta tecido testicular, inclusive o que sofreu ressecção da cauda do epidídimo ao invés da criptorquidectomia, o que segundo Trotter e Aanes (1981), é erro técnico comum.

\section{CONCLUSÕES}

A dosagem da testosterona sérica por radioimunoensaio é útil no diagnóstico de criptorquismo em eqüinos. Cavalos criptórquios produzem testosterona em quantidades comparáveis às de garanhões normais.

\section{REFERÊNCIAS BIBLIOGRÁFICAS}

ACKLAND, H.M. Reproductive system: Male. In: McGAVIN, M.D.; CARLTON, W.W.; ZACHARY, J.F. Thomson's special veterinary pathology. 3.ed. St. Louis: Mosby, 2001. p.635652.

ARIGHI, M.; BOSU, W.T.K. Comparison of hormonal methods for diagnosis of cryptorchidism in horses. Equine Vet. Sci., v.9, p.20-26, 1989.

ARIGHI, M.; BOSU, W.T.K.; RAESIDE, J.I. Hormonal diagnosis of equine cryptorchidism and histology of the retained testes. Proc. Am. Assoc. Equine Practit., v.31, p.591-602, 1986.

ARIGHI, M.; HORNEY, J.D.; BOSU, W.T.K. Noninvasive inguinal approach for cryptorchidectomy in thirty-eight stallions. Can. Vet. J., v.29, p.346-349, 1988.

BERGIN, W.C.; GIER, H.T.; MARION, G.B. et al. A developmental concept of equine cryptorchism. Biol. Reprod., v.3, p.82-92, 1970.

CORYN, M.; De MOOR, A.; BOUTERS, R. et al. Clinical, morphological and endocrinological aspects of cryptorchidism in the horse. Theriogenology, v.16, p.489-496. 1981.

COX, J.E. Blood test for equine cryptorchidism. Vet. Rec., v.110, p.211, 1982.

COX, J.E. Testosterone concentrations in normal and cryptorchid horses. Response to human chorionic gonadotrophin. Anim. Reprod. Sci., v.18, p.43-50, 1989.

COX, J.E.; EDWARDS, G.B.; NEAL, P.A. An analysis of 500 cases of equine cryptorchidism. Equine Vet. J., v.11, p.113-116, 1979.

COX, J.E.; EDWARDS, G.B.; NEAL, P.A. Suprapubic paramedian laparotomy for equine abdominal cryptorchidism. Vet. Rec., v.97, p.428-432, 1975.

COX, J.E.; REDHEAD, P.H.; DAWSON, F.E. Comparison of the measurement of plasma testosterone and plasma oestrogens for the diagnosis of cryptorchidism in the horse. Equine Vet. J., v.18, p.179-182, 1986.

COX, J.E.; WILLIAMS, J.H.; ROWE, P.H. et al. Testosterone in normal, cryptorchid and castrated male horses. Equine Vet. J., v.5, p.85-90. 1973.

HAYES, H.M. Epidemiological features of 5009 cases of equine cryptorchism. Equine Vet. J., v.18, p.467-471. 1986.

LADDS, P.W. The male genital system. In: JUBB, K.V.F.; KENNEDY, P.C.; PALMER, N. Pathology of domestic animals. 4.ed. San Diego: Academic Press, 1993. v.3, p.471-529.

LEIPOLD, H.W.; DeBOWES, R.M.; BENNETT, B.S. et al. Cryptorchidism in the horse: genetic implications. Proc. Am. Assoc. Equine Practit., v.31, p.579-589, 1986.

LOWE, J.; HIGGINBOTHAM, R. Castration of abdominal cryptorchid horses by a paramedian laparotomy approach. Cornell Vet., v.59, p.121126, 1969.

MARQUES, J.A.; FERREIRA, H.I. Orquiectomia nos eqüinos criptorquídicos em posição quadrupedal. Ars Vet., v.3, p.219-221. 1987.

NASCIMENTO, E.F.; SANTOS, R.L. Patologia da reprodução dos animais domésticos. 2.ed. Rio de Janeiro: Guanabara Koogan, 2003. p.94-95.

SILVA, L.A.F.; ALMEIDA, C.F.; OLIVEIRA, M.P. et al. Tratamento do criptorquidismo em eqüinos utilizando as abordagens cirúrgicas paraprepucial e escrotal. Rev. Bras. Ciên. Vet., v.9, p.115-117. 2002. Suplemento.

SMITH, J.A. The development and descent of the testis in the horse. Vet. Annu., v.15, p.156$161,1975$. 
STANIC, M.N. Castration of cryptorchids. Mod. Vet. Pract., v.41, p.30-33, 1960.

STICKLE, R.L.; FESSLER, J.F. Retrospective study of 350 cases of equine cryptorchidism. $J$. Am. Vet. Med. Assoc., v.172, p.343-346. 1978.

TROTTER, G.W.; AANES, W.A. A complication of cryptorchid castration in three horses. J. Am. Vet. Med. Assoc., v.178, p.246248. 1981.

VALDEZ, H.; TAYLOR, T.S.; McLAUGHLIN, S.A. et al. Abdominal cryptorchidectomy in the horse, using inguinal extension of the gubernaculum testis. J. Am. Vet. Med. Assoc., v.174, p.1110-1112, 1979.

WILSON, D.G.; REINERTSON, E.L. A modified parainguinal approach for cryptorchidectomy in horses: an evaluation in 107 horses. Vet. Surg., v.16, p.1-4, 1987.

WRIGHT, J.G. Laparo-orchidectomy in the horse with abdominal cryptorchidism. Vet. Rec., v.72, p.57-60, 1960.

WRIGHT, J.G. The surgery of the inguinal canal in animals. Vet. Rec., v.75, p.1352-1365, 1963. 